\title{
Familial or sporadic hemiplegic migraine
}

INSERM

\section{Source}

INSERM. (1999). Orphanet: an online rare disease and orphan drug data base. Familial or sporadic hemiplegic migraine. ORPHA:569

Hemiplegic migraine $(\mathrm{HM})$ is a rare variety of migraine with aura characterized by the presence of a motor weakness during the aura. Hemiplegic migraine has two main forms depending on the familial history: patients with at least one first- or second-deg ree relative who has aura including motor weakness have familial hemiplegic migraine (FHM); patients without such familial history have sporadic hemiplegic migraine (SHM). 